\title{
Talent Management, Work Engagement and Service Quality Orientation of Support Staff in a Higher Education Institution
}

\author{
Nicolene Barkhuizen \\ Puleng Mogwere \\ Department of Industrial Psychology \\ North-West University, Mafikeng Campus, South Africa \\ nicolene.barkhuizen@nwu.ac.za \\ Nico Schutte \\ Department of Public Administration \\ North-West University, Mafikeng Campus, South Africa
}

Doi:10.5901/mjss.2014.v5n4p69

\begin{abstract}
Despite significant inroads being made in the concept of talent management, the application thereof in higher education institutions remains scant, especially among support staff. This research investigated the relationship between Talent Management, Work Engagement and Service Quality Orientation of support staff $(N=60)$ in a South African Higher Education Institution. A Human Capital Index, Utrecht Work Engagement Scale and Servqual were administered. The results showed a positive significant relationship between some of the talent management dimensions and work engagement. The results showed a significant positive relationship between all the work engagement dimensions and some of the servqual dimensions. The results showed no significant relationship between Talent Management and Service Quality Orientation. This research highlighted the importance of the effective application of Talent Management practices for support staff in higher education institutions and the outcomes thereof on positive work related behaviours such as work engagement and service quality.
\end{abstract}

Keywords: Talent Management, Work Engagement, Service Quality Orientation, Support Staff, Higher Education Institutions

\section{Introduction}

Talent Management is a concept increasingly on the minds of managers and practitioners as it becomes more difficult to attract, develop and retain talented employees in a fierce competitive business world. This situation is problematic in the South African context as The Global Competiveness Report continues to rank the country low in terms of labour marker efficiency and people development (World Competitiveness Report, 2012). A country's international competitiveness and growth of the knowledge community depends on its population having a strong and sustainable higher educational sector. Any institution that offers higher education is driven by a quality faculty which, become an invaluable asset for such an institution. Furthermore, attracting and retaining quality faculty is very important to educational institutions as a low faculty retention rate might create both monetary and academic consequences (Rensselaer Polytechnic Institute, 2012). Without well qualified and committed staff, no academic institution can ensure sustainability and quality over the long term (Pienaar \& Bester, 2008).

Support staff in higher education institutions plays a key role in creating a high-quality customer service and representing the institution's competence. In particular, their attitudes and behaviours can have a significant influence on students and clients satisfaction and perceptions of the quality of service (Burke, Koyuncu, Fiksenbaum \& Tekin, 2013). Smerek and Perterson (2007) regard support staff as the key component in higher education institutions, because their responsibility to take care of the day to day operations of the institution. Banata and Kuh (cited in Rothmann \& Essenko, 2007) also add that it is almost impossible to achieve a faculty or the department's objectives for the intellectual and personal development without the assistance of support staff. Rothmann and Essenko (2007) further explains that support staff plays a major role in the creation and improvement of knowledge and modernization in HEI. Krücken, Blümel and Kloke (2013) maintain that constant changes in the higher educational environment will result in a more intensive recruitment of specialized management staff and a subsequent growth in non-academic staff. 
Talent management of key faculty still seems to be neither a strategic or operational priority in many higher education institutions (Riccio, 2010; Theron, Barkhuizen \& Du Plessis, in press). Szekeres (cited in Hurlimann, March \& Robins, 2013) alludes to the fact that there is often a complete disregard for support staffs' work in higher education. Support staff faces constant demands form management, academic staff (Ablanedo-Rosas, Blevins, Gao, Teng \& White, 2011) without any corresponding recognition. Pick, Teo and Yeung (2012) for example found that support staff faces significant obstacles in higher education in terms of career development opportunities, management support, poor performance management systems, unrealistic deadlines, a lack of participation in decision-making and poor compensation. Burke et al. (2013) maintain that effective human resource management practices which also include talent management practices can increase the levels of employee engagement and in turn enhance the service quality provided to clients and overall institutional performance.

The main objective of this research was to determine the relationship between the talent management, work engagement and service quality orientation of support staff in a South African higher education institution. No studies currently exist relating talent management to the work engagement and service quality of support staff in higher education institutions. A number of researchers highlights that fact that research on support staff in higher educational setting are still scant (see Ablanedo-Rosas et al., 2013; Hurlimann et al., 2013; Pick et al., 2012) despite the growing importance of this occupational group (Sebalj, Holbrook, \& Bourke, 2012). Riccio (2010) refers to Lynch (2007) who maintains that higher education institutions, as producers of knowledge, should value the talent management of their staff to remain competitive and relevant in a knowledge economy. Against this background we believe that the talent management of support staff and the impact thereof on their work engagement and service quality orientation is imperative from a research point of view.

The next section of the paper will highlight the theory and research hypotheses relating to the interactive relationships between talent management, work engagement and service quality. Thereafter, a discussion of the research approach and method will be provided, followed by the results of the research. Finally the article concludes with a discussion of the research results, as well as recommendations for further research.

\section{Theory and Hypotheses}

\subsection{Talent Management and Work Engagement}

Talent management can be defined as the implementation of integrated human resource strategies to attract, develop, retain and productively utilize employees with the required skills and abilities to meet current and future business needs (Kontoghiorges \& Frangou, 2009). The effective talent management of employees has shown to increase their well-being (Barkhuizen \& Stanz, 2010), job satisfaction (Magolego, Barkhuizen \& Lesenyeho, 2013), psychological contract (Mtila, Barkhuizen \& Mokgele, 2013), organisational energy (Mpofu \& Barkhuizen, 2013) and decreased turnover intentions (Barkhuizen \& Veldman, 2012; Du Plessis, Stanz \& Barkhuizen, 2013). Though several studies among South African government institutions pointed out that talent management practices are generally poorly applied or largely ignored (see Barkhuizen, 2013; Du Plessis et al., 2010; Magolego et al., 2013; Mtila et al., 2013; Mpofu \& Barkhuizen, 2013).

Work engagement is a positive work-related state of mind that consists of vigour, dedication and absorption (Schaufeli \& Barkker, 2003). Vigour is characterised by high levels of energy and mental resilience while working, the willingness to invest effort in one's work and the persistence even in the face of difficulties. Dedication is characterised by a sense of significance, enthusiasm, inspiration, pride and challenge. Finally, absorption is characterised by being totally and happily immersed in one's work, to the extent that it is difficult to detach oneself from it (see Schaufeli \& Bakker, 2001). Engaged employees show higher levels of energy and identification towards their work, which in turn has a positive impact on job performance and financial turnover of an organisation (Bakker \& Demerouti, 2008; Bakker, Schaufeli, Leiter \& Taris, 2008).

According to Bhatnagar (2007) effective talent management policies and practices demonstrate a commitment to human capital which in turn can result in higher level of work engagement amongst employees. In fact, many organisations implement talent management practices with the objective of enhancing employee engagement and decreasing staff turnover (Roper, 2009). Workers with a high level of work engagement are more likely to provide better customer service (Gracia, Salanova, Grau \& Cifre, 2012).

$H 1$ : There is a significant positive relationship between talent management and work engagement of support staff 


\subsection{Talent Management and Service Quality}

The effective talent management of staff are widely recognised as key to the effective service delivery and customer satisfaction (see Gracia et al., 2013; Osman, Berbary, Sidani, Al-Ayoubi \& Emrouznejad, 2011; Popescu, Avram \& Dana, 2012) Service Quality is defined by the relationship between the expectations of customers and how they perceive their experience (Parasuraman, Zeithaml \& Berry, 1988). Service quality can be measured in terms of five main dimensions namely Tangibles, Assurance, Responsiveness, Reliability and Empathy (Parasuraman at al., 1988). Tangibles refer to the appearance of physical facilities, equipment, personnel and communication materials. Assurance refers to knowledge and courtesy of employees and their ability to convey trust and confidence. Responsiveness refers to the willingness of employees to help customers and provide prompt service. Reliability refers to the ability to perform the promised service dependably and accurately. Empathy refers to the caring, individualized attention that organisations provide its customers.

Schneider, White and Paul (1998) maintain that employees can only deliver a quality service if the organisation supports them through resources, training, management practices, and assistance. In particular talent practices such as skills training, competence development, career development plans and sound performance appraisal systems are key to the enhancement of service quality (Osman et al., 2011; Popescu et al., 2012). Other researchers also highlighted talent attraction and retention practices as an important determinant of quality service delivery (Scott \& Revis, 2008; Zheng, 2009).

$\mathrm{H}$ 2: There is a significant positive relationship between talent management and service quality orientation of support staff.

\subsection{Work Engagement and Service Quality}

Burke et al. (2013) maintains that work engagement is an important concept for organisations to consider in unleashing the talents of their employees. Work engagement has been constantly related to positive work-related outcomes such as organisational commitment, job satisfaction, motivation, increased well-being and performance. A study done by Gracia, Salanova, Grau and Cifre (2013) done among 8000 business units in 36 companies found positive correlations between employee engagement, customer satisfaction, loyalty, profitability, productivity and employee turnover. In this study business units with higher levels of work engagement tend to perform better compared to those business units with lower levels of work engagement. Burke et al. (2013) refer to several studies where the work engagement of employees increased customer loyalty and employee performance (Salanova et al. 2005; Halbesleben 2010). Finally Bakker, Demerouti and Verbeke (cited by Bakker et al., 2008, p. 194) showed that engaged employees "perform well and are willing to go the extra mile".

$\mathrm{H}$ 3: There is a significant positive relationship between work engagement and service quality orientation of support staff

\section{Research Design}

\subsection{Sampling}

The target population for this research included support staff from a higher education institution in South Africa. Two hundred (200) questionnaires were sent out by means of hard copy with 65 questionnaires returned. Of these only 60 questionnaires were usable for analyses which resulted in a final response rate of $33 \%$. Most of the respondents were male (51.7\%), Setswana (55\%), representative of the African (Black) ethnic group (71.7\%) and aged between 20 and 39 years (56.7\%). Respondents were primarily in possession of a diploma (35\%), had between 0-10 years of work experience (56.7\%) and have been working in their current between 0-10 years (81.7\%). Most of the respondents had 0 changes of promotion (66.7\%) and worked between 0 - 40 hours per week (60\%).

\subsection{Measurements}

\subsubsection{The Human Capital Index}

The Human Capital Index (adapted version) of the Human Capital Institute (2008) was used in the current study to 
measure the perceived talent management practices by the research participants. The Index consist of 41 items and measure eight Talent Management Practices: Management Commitment, Talent Review Process, Workforce Planning, Staffing, Talent Acquisition, Talent Development, Performance Management and Talent Retention. Respondents are first required to indicate the extent of their agreement with each statement on a five-point Lickert-type scale ranging from strongly disagree (1) to strongly agree (5). Respondents are secondly required to indicate the importance of the talent management practices from Not (1) to Crucial (5). This questionnaire has been validated in several South African studies (see Barkhuizen, 2013; Magolego et al., 2013; Mpofu \& Barkhuizen, 2013; Mtila et al., 2013).

\subsubsection{Utrecht Work Engagement Scale}

The Utrecht Work Engagement Scale (UWES) (Schaufeli \& Bakker, 2003) was used to measure the levels of engagement. Three dimensions of engagement can be distinguished, namely Vigour ( 6 items; i.e., "I am bursting with energy in my work"), Dedication (5 items; i.e., "I find my work full of meaning and purpose") and Absorption (6 items; i.e., "When I am working, I forget everything else around me"). Engaged individuals are characterised by high levels of Vigour and Dedication and also elevated levels of Absorption. The questionnaire showed acceptable internal consistencies in several South African studies (see Barkhuizen \& Rothmann, 2006; Bell \& Barkhuizen, 2011).

\subsubsection{SERVQUAL}

An adapted version of SERVQUAL scale was used to measure the service quality orientation of the respondents (Parasuruman et al., 1988). The questionnaire consists of 22 items and measures five dimensions, namely, reliability, tangibles, responsiveness, assurance and empathy. The items were rephrased to measure the respondents' orientation towards delivering a quality service. The questionnaire has been validated in the South African context (Barkhuizen \& Goosen, 2009).

\subsection{Statistical Analyses}

Statistical analysis was carried out using the SPSS Program (SPSS Inc, 2013). The reliability and validity of the $\mathrm{HCl}$, UWES and SERVQUAL were determined by means of exploratory factor analysis and Cronbach alpha coefficients. Pearson product-moment correlation coefficient was used to specify the relationship between talent management, work engagement and service quality orientation. A cut-off point of 0,30 (medium effect, Cohen, 1988) was set for the practical significance of correlation coefficients. In terms of statistical significance, a value at a $95 \%$ confidence interval level ( $p \leq$ $0,05)$ is set.

\section{Results}

\subsection{Factor and Reliability analyses}

The sample size limited the research in terms of carrying out a factor analyses on each of the measurements. As a result an exploratory factor analyses was done on the theoretical sub-scales of each of the measurements to uncover the underlying factor structures. The factor analyses revealed one underlying factor for each sub-scale. The sub-scale showed acceptable variance and item loadings. The descriptive results of the measurements and reliabilities of the measurements are reported in Table 1 below.

Table 1: Descriptive statistics and Alpha Coefficients: $\mathrm{HCl}$, UWES and SERVQUAL

\begin{tabular}{|l|c|c|c|c|c|}
\hline \multicolumn{1}{|c|}{ Scales } & Mean & SD & Skewness & Kurtosis & $\boldsymbol{\alpha}$ \\
\hline Talent Management & & & & & \\
\hline Management Commitment & 2.0528 & 3.84 & -0.41 & 0.56 & .917 \\
\hline Talent Review Process & 1.8385 & 1.65 & -0.38 & 0.48 & .902 \\
\hline Workforce Planning & 2.1944 & 2.56 & -0.34 & 0.15 & .901 \\
\hline Staffing & 2.9327 & 4.23 & -0.42 & 1.22 & .822 \\
\hline Talent Acquisition & 2.5324 & 3.04 & -0.32 & 0.73 & .871 \\
\hline Talent Development & 2.1147 & 2.52 & -0.26 & 0.30 & .948 \\
\hline
\end{tabular}




\begin{tabular}{|l|c|c|c|c|c|}
\hline Performance Management & 2.0789 & 1.76 & -0.42 & 0.33 & .910 \\
\hline Retention Strategies & 1.7477 & 2.24 & -0.20 & 0.96 & .842 \\
\hline \hline Work Engagement & & & & & \\
\hline Subscales & & & & & \\
\hline Vigour & 3.5033 & 1.58488 & -.198 & -.594 & .895 \\
\hline Dedication & 3.5806 & 1.56663 & -.194 & -.925 & .923 \\
\hline Absorption & 3.4917 & 1.69785 & -.406 & -.740 & .946 \\
\hline \hline Service ORIENTATION & & & & & \\
\hline Assurance & 5.1917 & .74981 & -1.432 & 2.661 & .856 \\
\hline Responsiveness & 5.1300 & .71575 & -1.104 & 1.863 & .929 \\
\hline Reliability & 5.2000 & .71781 & -1.149 & 1.306 & .887 \\
\hline Tangibles & 5.2333 & .75193 & -1.140 & 1.100 & .852 \\
\hline Empathy & 5.2583 & .75628 & -1.260 & 1.648 & .885 \\
\hline
\end{tabular}

The results in Table 1 show good to excellent reliabilities for the sub-scales of the three measurements. The mean values for the talent management sub-scales ranged between 1.7477 and 2.9327. The results clearly show that the respondents perceive that Talent Management practices are applied below average. The Talent Management practices that seemed most problematic included a lack of retention strategies, talent review processes, management commitment towards talent management and poor performance management systems. The results further showed that the respondents experience average levels of work engagement but high levels of service orientation.

Next a gap analyses and T-tests were done to determine if there are any significant differences between the current versus the importance of talent management practices. The results are reported in Table 2 below.

Table 2: Gap analyses between the current versus the importance of talent management practices

\begin{tabular}{|l|c|c|c|c|}
\hline & \multicolumn{2}{|c|}{ Mean } & Mean & \\
\cline { 1 - 2 } & Current & Importance & Difference & $\boldsymbol{p}$ \\
\hline Management Commitment & 2.0528 & 4.2500 & -2.1972 & $\mathbf{0 . 0 0 0 ^ { * * }}$ \\
\hline Talent Review Process & 1.8385 & 4.3688 & -2.5303 & $\mathbf{0 . 0 2 9}^{* *}$ \\
\hline Workforce Planning & 2.1944 & 4.3505 & -2.1560 & 0.668 \\
\hline Staffing & 2.9327 & 4.2840 & -1.3512 & 0.201 \\
\hline Talent Acquisition & 2.5324 & 4.4174 & -1.8850 & 0.340 \\
\hline Talent Development & 2.1147 & 4.4236 & -2.3089 & 0.919 \\
\hline Performance Management & 2.0789 & 4.3431 & -2.2642 & 0.263 \\
\hline Retention Strategies & 1.7477 & 4.4051 & -2.6574 & $\mathbf{0 . 0 0 5 ^ { * * }}$ \\
\hline
\end{tabular}

The results in Table 2 show that large gaps exist between the current application of talent management practices for support staff and the importance they attach to it. The largest gaps between current applications were observed between Talent Review Process, Retention Practices, Talent Development, and Management Commitment. The results further also showed that significant differences exist between current Management Commitment towards talent management practices as well as the importance thereof. Significant differences were also found between the current application and importance of Talent Review Processes and Retention Strategies.

The next section reports on the testing of the hypotheses.

\subsection{Testing of Hypotheses}

\subsubsection{Hypothesis 1}

H1: There is a significant positive relationship between Talent Management and Work Engagement of Support Staff 3 below.

The results of the correlation analyses between Talent Management and Work Engagement are reported in Table 
Table 3: Correlation Analyses between Talent Management and Work Engagement

\begin{tabular}{|l|c|c|c|}
\hline & Vigour & Dedication & Absorption \\
\hline Management Commitment & $.429^{* *}$ & $.362^{* *}$ & $.397^{* *}$ \\
\hline Talent Review Process & $.333^{* *}$ & $.303^{*}$ & $.326^{*}$ \\
\hline Workforce Planning & .201 & .217 & .223 \\
\hline Staffing & .091 & .116 & .153 \\
\hline Talent Acquisition & .143 & .225 & .245 \\
\hline Talent Development & $.344^{* *}$ & $.354^{* *}$ & $.381^{* *}$ \\
\hline Performance Management & $.268^{*}$ & $.294^{*}$ & $.332^{* *}$ \\
\hline Talent Retention & .116 & .155 & .166 \\
\hline
\end{tabular}

The results in Table 3 show that the current application of Talent Management Dimensions of Management Commitment, Talent Review Process and Talent Development were positively significantly related to all dimensions of work engagement (all medium effects). Performance Management was significantly positively related to Vigour and Dedication (small effects) and Absorption (medium effects). The results further showed the importance of Talent Review Processes was significantly positively related to vigour (medium effect). Staffing was positively significantly related to the all the dimensions of vigour (all medium effects). Talent Retention is positively significantly related to Vigour and Absorption (medium effects) and Dedication (small effect). Based on the above results Hypothesis 1 is partially accepted.

\subsubsection{Hypothesis 2}

$\mathrm{H}$ 2: There is a significant positive relationship between Talent Management and Service quality orientation of Support Staff

The results of the correlation analyses between talent management and service quality are reported in Table 4 below.

Table 4: Correlation Analyses between Talent Management and Service Quality

\begin{tabular}{|l|c|c|c|c|c|}
\hline & Assurance & Response & Reliable & Tangible & Empathy \\
\hline Management Commitment & .057 & -.001 & .055 & -.050 & -.053 \\
\hline Talent Review Process & -.017 & -.069 & -.029 & -.051 & -.059 \\
\hline Workforce Planning & -.006 & -.061 & -.001 & .012 & -.021 \\
\hline Staffing & .099 & .063 & .108 & .081 & .054 \\
\hline Talent Acquisition & .170 & .139 & .160 & .089 & .111 \\
\hline Talent Development & .194 & .109 & .105 & .107 & .105 \\
\hline Performance Management & .141 & .098 & .107 & .110 & .109 \\
\hline Retention Strategies & .102 & .036 & .035 & .086 & .010 \\
\hline
\end{tabular}

The results in Table 4 show no significant relationship between talent management and the service quality dimensions. Based on the above results Hypothesis 2 is rejected.

\subsubsection{Hypothesis 3}

H 3: There is a significant positive relationship between Work Engagement and Service Quality Orientation of Support Staff

The results of the correlation analyses between the work engagement and service quality dimensions are reported in Table 5 below.

Table 5: Correlation Analyses between Work Engagement and Service Quality

\begin{tabular}{|c|c|c|c|c|c|}
\hline & Assurance & Responsiveness & Reliability & Tangibles & Empathy \\
\hline Vigour &. $\mathbf{2 7 2 ^ { * }}$ &. $\mathbf{2 7 2}^{*}$ & .231 & .231 & .155 \\
\hline Dedication &. $\mathbf{2 8 4 ^ { * }}$ & .240 & .234 & .232 & .190 \\
\hline Absorption & $.282^{*}$ & $.262^{*}$ & .235 & .251 & .167 \\
\hline
\end{tabular}


The results in Table 5 show that all three dimensions of work engagement are significantly positively related to the Assurance Dimensions of Service Quality. The effects were small. Vigour and Absorption was significantly positively related to Responsiveness (small effects). No significant differences were found between the work engagement dimensions and the service quality dimensions of reliability, tangibles and empathy.

Based on the above results Hypothesis 3 is partially accepted.

\section{Discussion and Conclusion}

The main objective of this research was to determine the relationship between talent management, work engagement and service orientation of support staff in a South African Higher Education Institution. The results showed in general that all the talent management practices are poorly applied for support staff. In addition the results also showed that large gaps exist between the current applications versus the perceived importance of between Talent Review Process, Retention Practices, Talent Development, and Management Commitment. In line with previous studies this research also confirms that talent management practices remain problematic in government institutions such as higher education (Barkhuizen, 2013; Magolego et al., 2013; Mtila et al., 2013).

The results showed a significant positive relationship between some Talent Management and Work engagement dimensions. The effects were mostly small and medium. This implies that the better talent management practices are applied in the institution the higher the level of work engagement will be and vice versa. The positive relationship between talent management and work engagement can be explained by the fact that talent management practices were applied poorly in the institution and that the work engagement levels were average. Thus, the poor application in talent management practices will result in lower levels of work engagement. In line with previous research organisations need to implement effective talent management practices and policies to enhance the work engagement of employees (Bhatnagar, 2007; Gracia et al. 2013; Roper, 2009).

The results showed no significant relationship between talent management and the service quality orientation of support staff. These results are in contrast with previous research which suggests that Talent Management enhance the service delivery of employees (Gracia et al., 2013; Osman et al., 2011; Popescu et al., 2012). More research is needed to investigate the interactive relationship between talent management and service quality orientation.

Finally the results showed a positive relationship between work engagement and the service quality orientation of support staff. Even though the respondents reported average levels of work engagement, they still showed a high level of service quality orientation. Thus the higher the levels of work engagement the more likely support staff will be delivering quality service (Bakker \& Demerouti, 2008; Gracia et al., 2013; Halbesleben 2010; Salanova et al. 2005).

\subsection{Implications}

This research makes an important contribution towards expanding the limited empirical knowledge that currently exist on talent management and outcomes thereof on support staff in higher education institutions. The results clearly highlighted the problematic areas relating to talent management and the adverse impact thereof on positive work related states as work engagement. We have highlighted the importance of work engagement earlier in this paper as an important variable in unleashing talent in organisations. The results of this research also provide practical guidelines for higher education management to develop and implement appropriate talent management practices for key support staff to enhance their work engagement and service orientation.

\subsection{Limitations and Recommendations}

This research has some limitations. The limited empirical research available on support staff in higher education institutions meant that the results of the study had to be interpreted with caution. Limited reference could be made to previous research in the confirmation of findings. The sample small size limited the research in terms of further analyses such as differentiation between demographic groups in terms of the three variables of talent management, work engagement and service quality orientation. In addition this research only focused on one higher education institution. The results of this study can therefore not be generalised to other higher education institutions. Future research can benefit by expanding the sample to other higher education institutions as well. Larger sample sizes can also result in additional statistical analyses. Finally this research was cross-sectional in nature which means that the data was collected at one point in time. Future research can benefit from longitudinal studies so that cause and effect relationships 
can be test between talent management, work engagement and service quality orientation.

\subsection{Conclusion}

Support staff in higher education institution plays an important role in representing an institution's client service and competence. This research is a step towards recognising the unique contribution that support staff makes towards the effectiveness and competitiveness of higher education institutions. Therefore the effective talent management of support staff should become a strategic priority and management intervention in all higher education institutions.

\section{References}

Ablanedo-Rosas, J.H., Blevins, R.C., Gao, H., Teng, W., \& White, J. (2011). The impact of occupational stress on academic and administrative staff, and on students: an empirical case analysis. Journal of Higher Education Policy and Management, 33, (5), 553-564.

Bakker, A.B., \& Demerouti, E. (2008). Towards a model of work engagement. Career Development International, 13(3), $209-223$.

Bakker, A.B., Schaufeli, W.B., Leiter, M.P. \& Taris, T.W. (2008). Work engagement: An emerging concept in occupational psychology. Work \& Stress, 22(3), 187-200.

Barkhuizen, E.N. (2013). Employee Perceptions of Talent Management Practices in Local Government Institutions. In N. Delener, L. Fuxman, F. Lu, S. Rodrigues \& L. Rivera (Eds.), 15th Annual International Conference on Globalizing Businesses for the Next Century: Visualizing and Developing Contemporary Approaches to Harness Future Opportunities, Global Business and Technology Association, Helsinki, Finland (pp. 96-101), ISBN: 1-932917-08-X. USA, Gbata.

Barkhuizen, E.N., \& Goosen, X. (2009). The Relationship between Leadership and Service Performance of employees in South African financial institutions. Poster presented at the $14^{\text {th }}$ European Congress of Work and Organisational Psychology, Santiago, Spain, 13-16 May.

Barkhuizen, E. N., \& Rothmann, S. (2006). Work engagement of academic staff in South African higher education institutions. Management Dynamics, 15(1), 38-48.

Barkhuizen, E.N., \& Stanz, K.J. (2010). Linking organisational energy and individual well-being: The Influence of Leader's Talent Mindset. Paper published in the peer reviewed conference proceedings of the 12th Annual Conference of Global Business and Technology Association, Kruger National Park, South Africa, 5-9 July, pp. 50- 57, Gbata, USA, ISBN: 1-932917-06-3.

Barkhuizen, E.N., \& Veldsman, G. (2012, July). The impact of Talent Management Practices on the Retention of Employees in an Electricity Supply Company. Poster presented at the 30th International Congress of Psychology, Cape Town.

Bell, E., \& Barkhuizen, E.N. (2011). The relationship between barriers to change and work engagement of employees in a South African property management company. South African Journal of Industrial Psychology 37 (1), 1-11.

Bhatnagar, J. (2007). Talent management strategy of employee engagement in Indian ITES employees: Key to retention. Employee Relations. Vol. 29 Iss: 6 pp. $640-663$

Burke, R.J., Koyuncu, M., Fiksenbaum, L., \& Yasemin, T. (2013). Antecedents and Consequences of Work Engagement among Frontline Employees in Turkish Hotels, Journal of Transnational Management, 18, 3, 191-203.

Du Plessis, L., Stanz, K., \& Barkhuizen. (2010). The relationship between Perceived talent management practices, Perceived Organizational Support (POS), Perceived Supervisor Support (PSS) and Intention to quit amongst Generation Y employees in the Recruitment Sector. Paper presented at the 3rd Annual People and Organization's Conference, Wharton School, McGill University.

Gracia, E., Salanova, M., Grau, R. \& Cifre, E. (2013). How to enhance service quality through organizational facilitators, collective work engagement, and relational service competence. European Journal of Work and Organizational Psychology, 22, 1, 42-55.

Hurlimann, A., March, A., \& Robins, J. (2013). University curriculum development - stuck in a process and how to break free, Journal of Higher Education Policy and Management, 35, 6, 639-651.

Kontoghiorghes, C. \& Frangou, K. (2009). The association between talent retention, antecedent factors and consequent organizational performance. SAM Advanced Management Journal, 74, 1, 29-58.

Krücken, G, Blümel, A., \& Kloke, K. (2013). The Managerial Turn in Higher Education? On the Interplay of Organisational and Occupational Change in German Academia. Minerva, 51, 417-442.

Lynch, D. (2007). Can higher education manage talent? Retrieved June 11, 2009 from http://www.insidehighered.com/views /2007/11/27/lynch\#

Magolego. H., Barkhuizen, E.N. \& Lesenyeho, D.L. (2013). Talent Management and Job Performance: The Mediating Role of Job Satisfaction. In S.M. Lee \& G. Roodt (Eds.), 30th Pan Pacific Conference, Johannesburg, South Africa (pp. 132-135), ISBN: 1931649-27-3. PPBA

Mpofu. L., \& Barkhuizen, E.N. (2013). The Impact of Talent Management Practices on Employees in a Government Institution. In S.M. Lee \& G. Roodt (Eds.), 30th Pan Pacific Conference, Johannesburg, South Africa (pp. (129-131) ISBN: 1-931649-27-3. PPBA.

Mtila, J., Barkhuizen, E.N. \& Mokgele, R. (2013). Exploring the Application of Talent Management Practices in a Local Government Institution. In S.M. Lee \& G. Roodt (Eds.), 30th Pan Pacific Conference, Johannesburg, South Africa (pp. 66-68) ISBN: 1-93164927-3. PPBA. 
Osman, I., Berbary, L., Sidani, Y., Al-Ayoubi, B., \& Emrouznejad, A. (2011). Data envelopment analyses model for the appraisal and relative performance evaluation of nurses at an intensive care unit. Journal of Medical Systems, 35, 5, 1039-1062.

Pick, D., Teo, S., Yeung, M. (2012). Friend or Foe? New Managerialism and Technical, Administrative and Clerical Support Staff in Australian Universities. Higher Education Quarterly, 66, 1, 3-23.

Parasuraman, A., Zeithaml, V.A., \& Berry, L.L. (1988). SERVQUAL: A multi-item scale for measuring customer perceptions of service quality. Journal of Retailing, $64,12-42$.

Pienaar, C. \& Bester, C. L. (2008). The retention of academics in the early career phase: Empirical research. SA Journal of Human Resource Management, 6, 2, 32-41.

Popescu, C., Avram, R., \& Dana, M. (2012). New trends in Human Resource Management in the Hospitality Industry. Proceedings of the Scientific Conference AFASES, 185-190.

Rensselaer Polytechnic Institute. (2012). Faculty retention proves a major challenge for universities. ScienceDaily.16 Feb., 2012. [Online] Available: http://www.sciencedaily.com/releases/2012/02/120216144240.htm

Riccio, S. (2010). Talent Management in Higher Education: Developing Emerging Leaders within the administration of private colleges and universities. Educational Administration: Theses, Dissertations, and Student Research. Paper 34.

Rothmann, S., \& Essenko, N. (2007). Burnout of support staff in a higher education institution in the North West Province. South African Journal of Psychology, 37, 135-152.

Schaufeli, W.B. \& Bakker, A.B. (2003). UWES - utrecht work engagement scale: test manual. Department of Psychology, Utrecht University, Utrecht, available at: www.schaufeli.com

Schneider, B., White, S. S., \& Paul, M. S. (1998). 'Linking Service Climate and Customer Perceptions of Service Quality: Test of a Causal Model'. Journal of Applied Psychology, 83, 150-163.

Sebalj, D., Holbrook, A., \& Bourke, S. (2012). The rise of 'professional staff' and demise of the 'non-academic': a study of university staffing nomenclature preferences, Journal of Higher Education Policy and Management, 34 (5), 463-472.

Scott, B., \& Revis, S. (2008). Talent management in hospitality: graduate career success and strategies. International Journal of Contemporary Hospitality Management, 20 (7), 781-791.

Smerek, R. E. \& Peterson, Marvin, W (2007). Examining Herzberg's theory: Job satisfaction among non-academic employees at a research university. Research in Higher Education, 48(2), 229-250.

SPSS Inc. (2013). SPSS 21 for Windows. Chicago, IL: Author.

Theron, M., Barkhuizen, E.N., \& Du Plessis, Y. (in press). Managing the academic talent void: Investigating factors in academic turnover and retention in South Africa. South African Journal of Industrial Psychology, $40,1$.

World Economic Forum. (2012). Global Competitiveness Report 2012-2013.

Zheng, C. (2009). Keeping talents for advancing service films in Asia. Journal of Service Management, 20 (5), $482-502$. 